\title{
Nowcasting Economic Activity with Electronic Payments Data: A Predictive Modeling Approach*
}

\author{
Recibido: abril, 03 de 2018 - Aprobado: junio, 18 de 2018
}

DoI: http://dx.doi.org/10.12804/revistas.urosario.edu.co/economia/a.7205

\author{
Carlos León ${ }^{\dagger}$ \\ Fabio Ortega ${ }^{\ddagger}$
}

\begin{abstract}
Economic activity nowcasting (i.e., making current-period estimates) is convenient because most traditional measures of economic activity come with substantial lags. We aim at nowcasting ISE, a short-term economic activity indicator in Colombia. Inputs are the ISE's lags and a dataset of payments made with electronic transfers and cheques among individuals, firms, and the central government. Under a predictive modeling approach, we employ a non-linear autoregressive exogenous neural network model. Results suggest that our choice of inputs and predictive method enable us to nowcast economic activity with fair accuracy. Also, we validate that electronic payments data significantly reduce the nowcast error of a benchmark non-linear autoregressive neural network model. Nowcasting economic activity from electronic payment instruments data not only contributes
\end{abstract}

* The opinions contained in this document are the sole responsibility of the authors and do not commit Banco de la República or its Board of Directors. The authors are grateful to Hernando Vargas, Pamela Cardozo, Andrés González, Clara Machado, Carlos Huertas, Julián Pérez, Freddy Cepeda, Constanza Martínez, Daniel Parra, Aura Ciceri, Germán Muñoz, and Camilo Cárdenas for their comments and suggestions. Any remaining errors are the authors' own. [V.06.02.2018].

+ Financial Infrastructure Oversight Department, Banco de la República; CentER, Tilburg University; E-mail: cleonrin@banrep.gov.co/carlosleonr@hotmail.com; Banco de la República, carrera 7 \# 14-78 Bogotá (Colombia); tel.+57 1343 0731. [corresponding author].

$\ddagger \quad$ Financial Infrastructure Oversight Department, Banco de la República; E-mail: fortegca@banrep.gov.co

To quote this article: León, C., \& Ortega, F. (2018). Nowcasting economic activity with electronic payments data: a predictive modeling approach (2018). Revista de Economía del Rosario, 21(2), 381-407.

DoI: http://dx.doi.org/10.12804/revistas.urosario.edu.co/economia/a.7205 
to agents' decision making and economic modeling, but also supports new research paths on how to use retail payments data for appending current models.

Keywords: Forecasting, machine learning, neural networks, retail payments, NARX. JEL classification: C45, C53, E27.

\title{
Predicción inmediata de la actividad económica con datos de pagos electrónicos. Un enfoque de modelado predictivo
}

\begin{abstract}
Resumen
La predicción inmediata de la actividad económica (es decir, hacer estimaciones del período actual), es conveniente porque la mayoría de las medidas tradicionales de actividad económica se realizan con rezagos sustanciales. Nuestro objetivo es predecir el ISE, un indicador de actividad económica de corto plazo en Colombia. Las entradas son los rezagos del ISE y un conjunto de datos de pagos realizados entre individuos, empresas y el gobierno central, mediante transferencias electrónicas y cheques. Bajo un enfoque de modelado predictivo, empleamos un modelo de red neuronal exógena autoregresiva no lineal. Los resultados sugieren que nuestra elección de insumos y el método predictivo, nos permiten difundir la actividad económica con una precisión razonable. Además, validamos que los datos de pagos electrónicos reducen significativamente el error de predicción en un modelo de red neuronal autoregresiva de referencia. La predicción inmediata de la actividad económica con datos de los instrumentos de pago electrónicos, no solo contribuye a la toma de decisiones de los agentes y al modelado económico, sino que también soporta nuevas vías de investigación sobre cómo utilizar dichos datos en modelos actuales.
\end{abstract}

Palabras clave: pronóstico, aprendizaje de máquina, red neuronal, pagos minoristas, Red NARX. Clasificación JEL: C45, C53, E27.

\section{Predição imediata da atividade econômica com dados de pagamentos eletrônicos. Um enfoque de modelado preditivo}

\section{Resumo}

A predição imediata da atividade econômica (é dizer, fazer estimações do período atual), e conveniente porque a maioria das medidas tradicionais de atividade econômica realizamse com atrasos substanciais. O nosso objetivo é predizer o ISE, um indicador de atividade econômica de curto prazo na Colômbia. As entradas são os atrasos do ISE e um conjunto de dados de pagamentos realizados entre indivíduos, empresas e o governo central, mediante transferências eletrônicas e cheques. Sob um enfoque de modelado preditivo, empregamos um modelo de rede neuronal exógena auto regressiva não lineal. Os resultados sugerem que nossa eleição de insumos e o método preditivo, nos permitem difundir a atividade econômica com uma precisão razoável. Além disso, validamos que os dados de pagamentos eletrônicos reduzem significativamente o erro de predição em um modelo de rede neuronal auto regressiva de referência. A predição imediata da atividade econômica com dados dos instrumentos de pagamento eletrônico, não só contribui à tomada de decisões dos agentes e ao modelado econômico, senão que também suporta novas vias de pesquisa sobre como utilizar ditos dados em modelos atuais.

Palavras-chave: prognóstico, aprendizagem de máquina, rede neuronal, pagamentos minoristas, Rede NARX.

Classificação JEL: C45, C53, E27. 


\section{Introduction}

The lack of timely information about the current state of the economy is a well-recognized problem among policy makers (Evans, 2005). That explains why 'nowcasting', defined as "current-period estimates" (Galbraith \& Tkacz, 2017) or "the prediction of the present, the very near future and the very recent past" (Bańbura et al., 2013), has become a standard activity for central banks (Tiffin, 2016, Hinds et al., 2017).

Economic activity is one among many lagged key macroeconomic variables. Gross domestic product (GDP) estimates are released with a four-week lag in the United States and the United Kingdom; six in Japan; six or seven in the Euro area; eight in Canada; and up to one or two years in Lebanon (see Bańbura et al., 2013; Tiffin, 2016; Bragoli, 2017; Galbraith \& Tkacz, 2017). Short-term economic activity indicators attempt to reduce this lag. However, as most short-term indicators tend to rely on a subset of GDP inputs or other non-high-frequency and lagged variables, they usually have a non-negligible delay.

In the Colombian case, the national bureau of statistics (Departamento Administrativo Nacional de Estadística, DANE) releases GDP quarterly figures with an approximate two-month lag (DANE, 2017). The same bureau releases the Economic Monitoring Index (Indicador de Seguimiento a la Economía, ISE), which is a monthly indicator with an approximate two-month lag that provides the market with a dynamic index of economic activity (DANE, 2016). Consequently, an accurate current-period estimate of ISE could provide the central bank, financial market participants, and other economic agents (e. g., government, real sector) with better tools for decision-making and modeling.

Our aim in this article is to answer a single question: is it possible to nowcast changes in the ISE with a dataset of electronic payment instruments? ${ }^{1}$ Unlike most literature on economic activity nowcasting, we rely on electronic payments among individuals, firms, and the central government as high-frequency indicators (i. e., the inputs) from which reliable signals of economic activity are to be extracted. Using electronic payments as inputs is

1 A payment instrument enables the holder or user to transfer funds, such as cash, cheques, debit and credit cards, and electronic transfers. Cash is a non-electronic (i. e., physical) payment instrument. Cards and transfers are electronic payment instruments. Cheques are to be considered electronic payments because they are physical at their inception, but they are cleared electronically. As stated below, we focus on electronic transfers and cheques only. 
not fortuitous: they convey information about economic activity as they are representative of agents' expenditure.

As nowcasting is better understood as a prediction task, we undertake a predictive modeling approach (Shmueli, 2010) that relies on the well-documented performance and flexibility of artificial neural networks (ANNS) for prediction. Hence, unlike a traditional econometric approach, we do not attempt to test any causal theory or to explain which inputs excel as explanatory determinants of economic activity, but to attain an accurate out-of-sample prediction model by discovering complex structures in data that are not specified in advance. In this vein, following Shmueli (2010), Varian (2014) and Mullainathan and Spiess (2017), our approach departs from traditional econometric methods $(i$. e., explanatory modeling), and pertains to machine learning methods.

Evans (2005) and Giannonne et al. (2008) are among the first and most influential works on nowcasting economic activity. Our work is closely related to that of Galbraith and Tkacz (2017), who claim to be the first to make economic activity nowcasting based on payments data. However, there are several differences with Galbraith and Tkacz (2017) as we i) use a broader and larger spectrum of payment instruments that incorporates expenditures from individuals, firms, and the central government; ii) implement a Non-linear AutoRegressive eXogenous Artificial Neural Network model (NARX-ANN) that is documented for its predictive high-performance and flexibility; and iii) attempt to nowcast economic activity with a model that does not include traditional inputs (e.g., macroeconomic data, financial variables, surveys), but relies on electronic payment instrument data and lags of the corresponding economic activity indicator only.

Results suggest that a dataset containing ISE's lagged data and contemporary electronic payments data allows to make a fair current-period estimate of ISE's change circa two months before its release. That is, nowcasting economic activity with electronic payment instruments data and a NARX-ANN model is feasible. Also, results validate that electronic payments data significantly reduces the nowcast error of a benchmark autoregressive model. Therefore, we contribute to decision-making and modeling by providing a suitable nowcasting alternative for economic activity indicators. Furthermore, our work may be a starting point for other nowcasting attempts based on payments data.

\section{Data}

The term 'nowcasting' is a contraction for 'now' and 'forecasting', and has been used for a long time in meteorology and recently also in economics 
(Bańbura et al., 2013). It consists of exploiting the information that is available early and at higher frequencies to make a current-period or early estimate of a lagged or low-frequency variable.

Nowcasting economic activity entails two main challenges. First, finding a suitable set of high-frequency indicators (i. e., inputs) from which reliable signals of economic activity (i.e., outputs) are to be extracted. Second, selecting an appropriate prediction method for extracting reliable signals of economic activity that serve as fair current-period or early estimates of economic activity. This section presents how we tackle the first challenge.

\subsection{Output}

Literature on economic activity nowcasting is fairly abundant (Evans, 2005; Bell et al., 2014, Bec \& Mogliani; 2015, Bragoli, 2017). Most literature sets the GDP as the output variable. Our aim is to nowcast the ISE (Economic Monitoring Index). ISE is a monthly indicator of economic activity that combines information about the production of goods and services pertaining to the most important economic activities in Colombia. ${ }^{2}$ It is estimated and released by the Colombian bureau of statistics with an approximate two-month lag.

By choosing the ISE instead of GDP we attain a greater number of observed outputs to work with. The ISE is available monthly from January 2000 onward. As payment inputs are available from January 2001 onward (see inputs section below), working on GDP quarterly figures would restrict our sample to about 48 observations, whereas working on ISE provides 192 observations. Moreover, as it is harmonized with quarterly GDP figures, working on ISE provides a fair and coherent estimate of changes in economic activity (DANE, 2016).

Figure 1 exhibits ISE from January 2001 to December 2016; descriptive statistics and the logarithmic returns of ISE are reported in Table 6 and Figure 6 (in the Appendix). As electronic payments data is non-seasonally adjusted (i.e., seasonal patterns are not removed), we use the non-seasonally adjusted ISE, at constant prices. We work with the revised index instead of preliminary estimates; as highlighted by Bell et al. (2014), ultimately, it is the official data that is most important for policy makers.

2 It corresponds to 111 indicators that track the dynamics of nine economic activities that compose the GDP, and they are weighted according to their contribution to the value added to economic activity. See DANE (2016). 


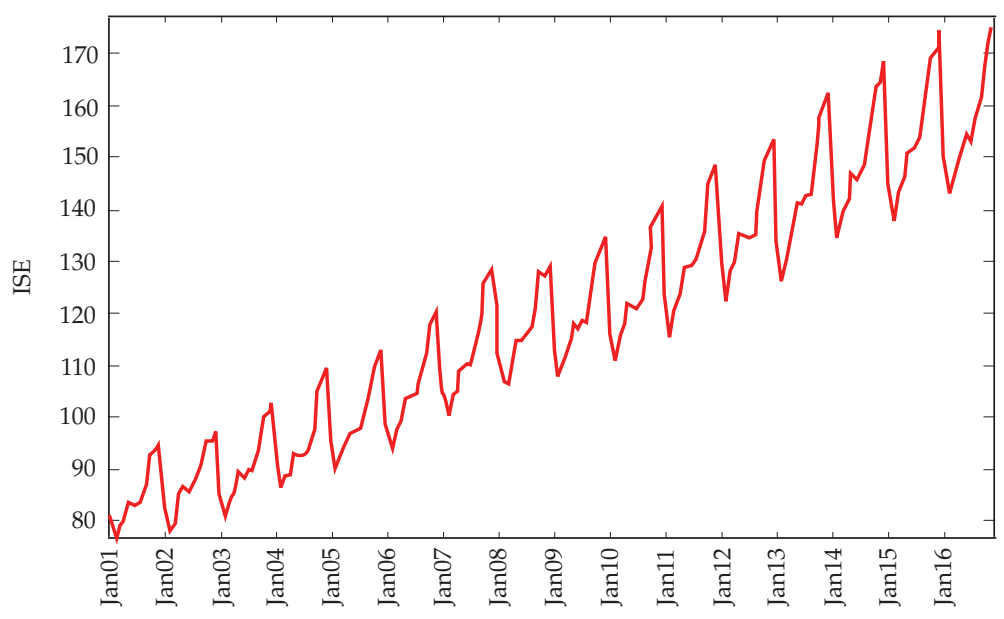

Figure 1. ISE. Non-seasonally adjusted, at constant prices, revised index Source: DANE.

\subsection{Inputs}

Most economic activity nowcasting literature relies on macroeconomic data, financial variables, surveys, or a mixture of them (Evans, 2005; Bańbura et al., 2013; Bell et al., 2014; Bec \& Mogliani, 2015; Bragoli, 2017). These inputs tend to convey a non-negligible lag (e.g., days, weeks or even months). Lately, research on how to nowcast economic activity from online data has surfaced. In that case, news articles, social media, web search data and other related sources are used to measure economic activity; for instance, McLaren (2011) and Choi and Varian (2012) illustrate how Google query indexes may be used for short-term economic activity prediction.

We choose electronic payment instrument data as our inputs for nowcasting economic activity. Our choice is unusual but has been already put into practice by Galbraith and Tkacz (2017). Galbraith and Tkacz use a set of electronic payments data comprising the value and number of operations from debit card transactions (i. e., point-of-sale payments) and 'small' cheques (i. e., under $\$ 50,000$ ) that clear through the Canadian banking system. They argue that both sources of payment information are representative of consumption expenditure, which is a major component of GDP, meaning that their set of inputs provide an incomplete but direct source of information on GDP changes. Also, they argue that electronic payments are available quickly and virtually free of sampling error. 
In our case we use a dataset comprising the value and number of operations from two different electronic payment instruments. First, from electronic transfers ordered by individuals, firms, and the central government, which are processed and cleared in both existing automated clearing houses ( $\mathrm{ACH})$, namely $\mathrm{ACH}$ Colombia and $\mathrm{ACH}$ Cenit; second, from cheques that are processed and cleared in the local cheque clearing house, Cedec. Unlike Galbraith and Tkacz (2017), we do not consider debit and credit card transactions because their contribution to the total value of electronic payments is rather low (i.e., below 5 percent), and because data is available with a lag that is incompatible with a nowcasting task, i.e. two or three months. Also, we do not limit cheques to being 'small'. A notable shortcoming common to both works is the absence of information about cash payments - the prevalent payment instrument in Colombia-. ${ }^{3}$

$\mathrm{ACH}$ Colombia is owned and managed by local banks. It fulfills the nowadays prevalent purpose of ACH s (McAndrews, 1994), namely to clear transfers between different banks regarding small repetitious payments among economic agents, such as payrolls, supplies, social security, mortgage installments, insurance premiums, dividends, and utility bills. As of 2016, twenty financial institutions clear their clients' transfers in Асн Colombia. On the other hand, ACH Cenit is owned and managed by the central bank. Its main function is processing central government's payments (e. g., payrolls, transfers to municipalities, public social security); thus, its main participant is the central government, which contributes with about 87 percent of its transfers by value (Banco de la República, 2017). Regarding cheques clearing, Cedec is owned and managed by the central bank as well. As exhibited in Table 7 (in the Appendix), as of 2016, payments processed in ACH Colombia, ACH Cenit and Cedec account for 96 and 38 percent of the value and number of operations, respectively, of all electronic payments cleared and settled among banks. ${ }^{4}$

Hence, our argument for using electronic payment instruments data is similar to that of Galbraith and Tkacz (2017). By using a broad set of electronic payments ordered by individuals, firms and the central government we aim at providing a direct and comprehensive source of information about expenditure dynamics of individuals, and the corporate and public sectors.

3 It has been established that there is a strong preference to use cash (i.e., pay and accept) in the Colombian case (Banco de la República, 2017).

4 As of 2016 (Banco de la República, 2017), the value and number of cheques cleared in banks' books (i.e., not cleared and settled among banks in Cedec) account for about 25 and 44 percent of all cleared cheques, respectively. The value and number of electronic transfers cleared in banks' books account for about 72 and 53 percent, respectively. 
That is, from the national income identity, our choice of inputs attempts to incorporate consumption, investment and government expenditure to economic activity nowcasting. Nonetheless, our source of information is partial: We lack data corresponding to some payment instruments (e. g., cash, credit and debit cards), and to transfers and cheques cleared and settled in the books of banks (i. e., not processed in a clearing house) —among others-.

Figure 2 exhibits the six inputs from January 2001 to December 2016. Inputs are non-seasonally adjusted; those corresponding to values are at constant prices - deflated by the consumer price index-. Descriptive statistics and visual inspection (Table 6 and Figure 7, in the Appendix) reveal that all series are to be considered non-normally distributed (except the number of operations of (edec) and potentially heteroscedastic. As in Galbraith and Tkacz (2017), inputs are monthly aggregates of daily transactions, and they are available simultaneously; issues related to mixed-frequency or asynchronous data are absent.
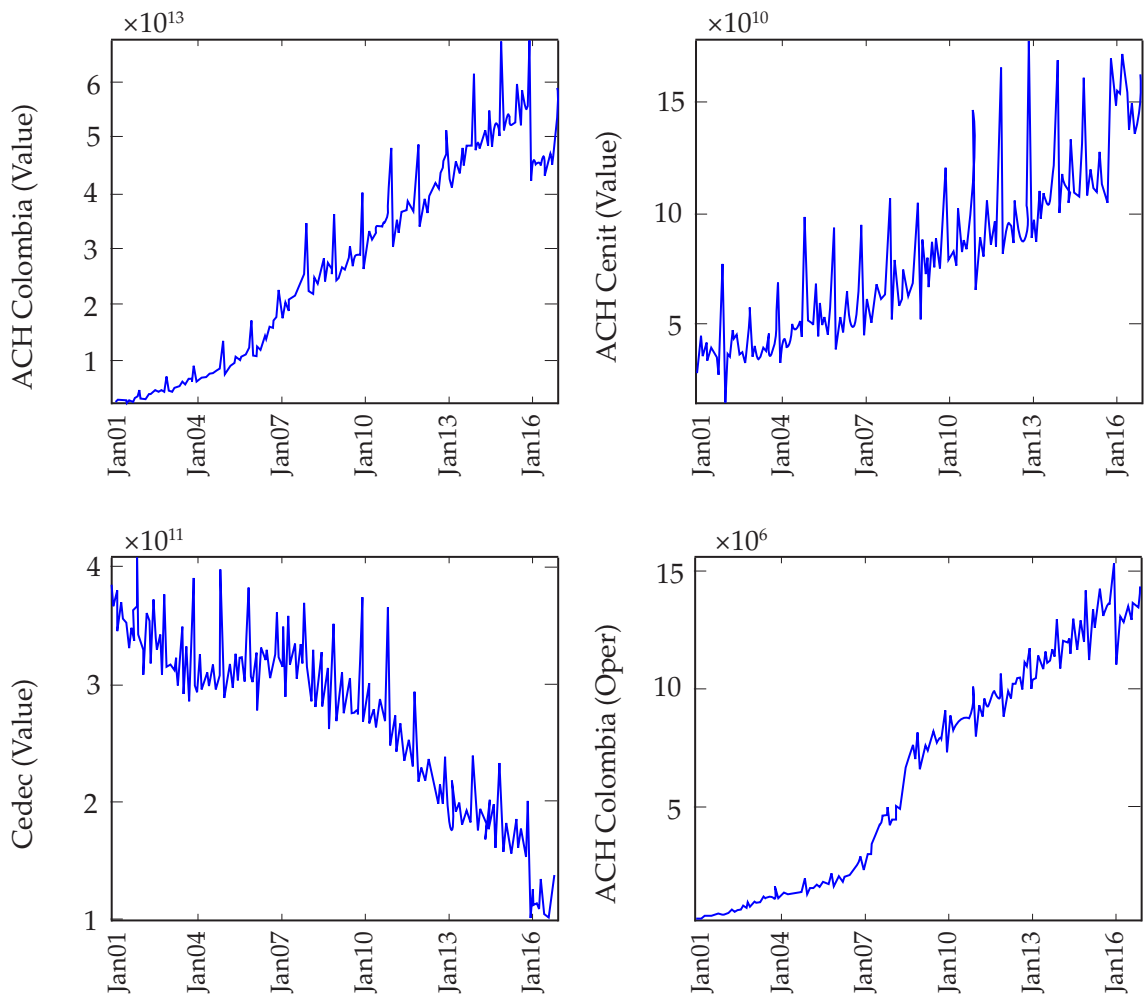

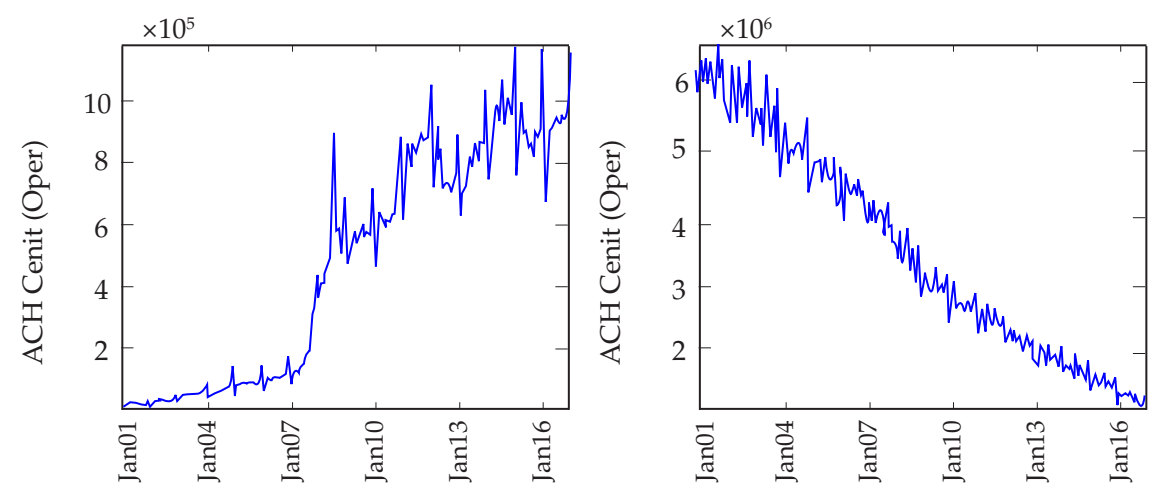

Figure 2. Electronic payment instruments data. Non-seasonally adjusted First row presents the value (in constant Colombian pesos, deflated by the consumer price index) and the second the number of operations.

Source: AcH Colombia and Banco de la República.

Figure 2 and Figure 7 (in the Appendix) suggest that inputs display a seasonal behavior that resembles that of ISE (in Figure 1 and Figure 6 in the Appendix). The correlation matrix between ISE and the six inputs reveals that there is some degree of linear dependence among series' logarithmic returns.

Table 1. Correlation matrix of output and inputs

\begin{tabular}{lcccccc}
\hline \multicolumn{1}{c}{ Variable } & 1 & 2 & 3 & 4 & 5 & 6 \\
\hline 1. ISE & & & & & & \\
2. AcH Colombia (Value) & .668 & & & & & \\
3. AcH Cenit (Value) & .506 & .681 & & & & \\
4. Cedec (Value) & .569 & .849 & .512 & & & \\
5. AcH Colombia (Oper.) & .611 & .894 & .589 & .814 & & \\
6. AcH Cenit (Oper.) & .524 & .780 & .733 & .658 & .803 & \\
7. Cedec (Oper.) & .546 & .789 & .414 & .861 & .828 & .652 \\
\hline
\end{tabular}

Estimated on logarithmic returns of monthly series (191 observations); inputs corresponding to values are at constant prices, deflated by the consumer price index.

Source: DANE, ACH Colombia and Banco de la República; authors' calculations.

Also, it is rather clear that the series disclose a well-known dynamic in electronic payment instruments in the Colombian case: the decay of cheques as payment instruments and the simultaneous rise of electronic transfers (see Table 7, in the Appendix). Therefore, it is worth highlighting that inputs not only reflect economic activity dynamics but also the evolution of payment 
instruments. As suggested by Galbraith and Tkacz (2017), using all inputs in a convenient manner - instead of using each one of them in isolation-should allow avoiding false signals about economic activity that may be related to the evolution of payment technology and habits.

\section{Prediction Method}

Forecasting and nowcasting are, by definition, prediction problems. Accordingly, machine learning approaches, which are intended for predictive modeling (Shmueli, 2010; Varian, 2014), have been used for forecasting and nowcasting economic activity. For instance, Tkacz and Hu (1999) and Aiken (2000) use ANNs to forecast the GDP of Canada and the United States; Tiffin (2016) uses elastic net regression and random forests to nowcast GDP in Lebanon; and Hinds et al. (2017) use elastic net regression in the United Kingdom's GDP case. However, most nowcasting literature is about econometric approaches. ${ }^{5}$

Three main reasons support our choice of machine learning in the form of an ANN for this prediction problem. First, given enough hidden layers and enough training samples, ANNs can closely approximate any function, thus they are able to deal with non-linear relationships between factors in the data (Bishop, 1995; Han \& Kamber, 2006; Demyanyk \& Hasan, 2009; Sarlin, 2014; Hagan et al., 2014). This has been reported by Tkacz and Hu (1999) and Zukime and Junoh (2004) as the most plausible reason for ANNs delivering improved forecast accuracy over linear methods when forecasting GDP in the Canadian and the Malaysian cases, respectively. Second, ANNs make no assumptions about the statistical properties of the data (Zhang et al., 1999; Aiken, 2000; Zukime \& Junoh, 2004; McNelis, 2005; Demyanyk \& Hasan, 2009; Sarlin, 2014). This is particularly convenient in our case as the output and most inputs exhibit non-normal distributions and appear to display some degree of heteroscedasticity (see Table 6, Figures 6 and 7, in the Appendix). Finally, ANNs have proven to be very effective in time series prediction problems, even better than standard econometric approaches (Kohzadi et al., 1995; Zhang et al., 1999; Misas et al., 2003; McNelis, 2005; Jalil \& Misas, 2006; Han \& Kamber, 2006; Chaudhuri \& Ghosh, 2016; Di Piazza et al., 2016). This is key in our case because, again, nowcasting is a prediction task.

The main disadvantage of ANNs, commonly known as the "black box criticism", is related to results' opacity and limited interpretability (Han \&

5 A review of econometric approaches to economic activity nowcasting is beyond the scope of this paper. A comprehensive review is presented in Bańbura et al. (2013). 
Kamber, 2006; Angelini et al., 2008; Witten et al., 2011; Chakraborty \& Joseph, 2017). However, as the black box criticism comes from a desire to tie down empirical estimation with an underlying economic theory (McNelis, 2005), this disadvantage is not an issue in our case: our only goal is to test whether electronic payment instruments data and an ANN are able to nowcast economic activity with fair precision - no underlying economic theory is to be tested-. We do not aim at producing good estimates of parameters that underlie the relationships between inputs and outputs: we aim at good output estimation. Our implementation of ANNs does not intend to yield a policy model, but only a nowcasting model.

\subsection{The NARX Artificial Neural Network Model}

In the case of time-series econometric models, a commonly used model is the linear autoregressive exogenous model (ARX). In this model [1], the output variable $\left(y_{t}\right)$ is modeled as a linear function of $k$ lagged $y_{t}$ variables and $h$ exogenous variables $\left(x_{t}\right)$. Solving this linear closed-form problem consists of minimizing the sum of square differences between observed and estimated output variables, $y_{t}$ and $\hat{y}_{t}$, respectively.

$$
y_{t}=\sum_{i=1}^{k} \beta_{i} y_{t-i}+\sum_{j=1}^{h} \rho_{j} x_{j, t}+\epsilon_{t}
$$

The simplicity of the ARx model entails a great shortcoming. The linear approximation may not be flexible enough to model a system in a complete manner, as there may be non-linear processes in the data. A non-linear autoregressive exogenous model may provide a more general and convenient approach to this type of problem.

Based on Lin et al. (1996), let $\Omega$ represent a non-linear function, and $k$ and $m$ the output and inputs lag order, respectively, a Non-linear AutoRegressive eXogenous (NARX) model may be represented as in [2]. In this case, the output variable $\left(y_{t}\right)$ is modeled as a non-linear function $\Omega$ of $k$ lagged $y_{t}$ variables and $m$ lagged exogenous variables $\left(x_{t}\right)$.

$$
y_{t}=\Omega\left[x_{t}, x_{t-1}, \ldots, x_{t-m}, y_{t-1}, \ldots, y_{t-k}\right]
$$

Lin et al. (1996) suggest that the non-linear function $\Omega$ may be approximated by an ANN structure, i. e., a NARX-ANN model. Unlike standard econometric approaches to time-series problems, the NARX-ANN model can efficiently be 
used for modeling non-stationary and non-linear dynamic systems (see Mahmoud et al., 2013; Chaudhuri \& Ghosh, 2016; Di Piazza et al., 2016).

In the sample structure exhibited in Figure 3, the output is modeled as a two-layer ANN. The first layer, also known as the 'hidden layer', consists of two tapped delayed lines (TDL) that contain the vectors of lagged inputs; three bias scalar terms $\left(b_{1}^{1}, b_{2}^{1}, b_{3}^{1}\right)$ with a constant input of 1 ; and all $w^{1}$ weights that connect each input with the three neurons (i.e., the sum operators and their corresponding activation functions, $f^{1}$ ). The second layer, also known as the 'output layer', consists of a single neuron with an operator that sums the product of the weights $\left(w_{1,1}^{2}, w_{2,1}^{2}, w_{3,1}^{2}\right)$ and the result from the neurons in the first layer $\left(f^{1}\left(n_{1}^{1}\right), f^{1}\left(n_{2}^{1}\right), f^{1}\left(n_{3}^{1}\right)\right)$; one bias scalar term, $b_{1}^{2}$, with a constant input of 1 ; and the second activation function $\left(f^{2}\left(n_{1}^{2}\right)\right)$, which yields the output.

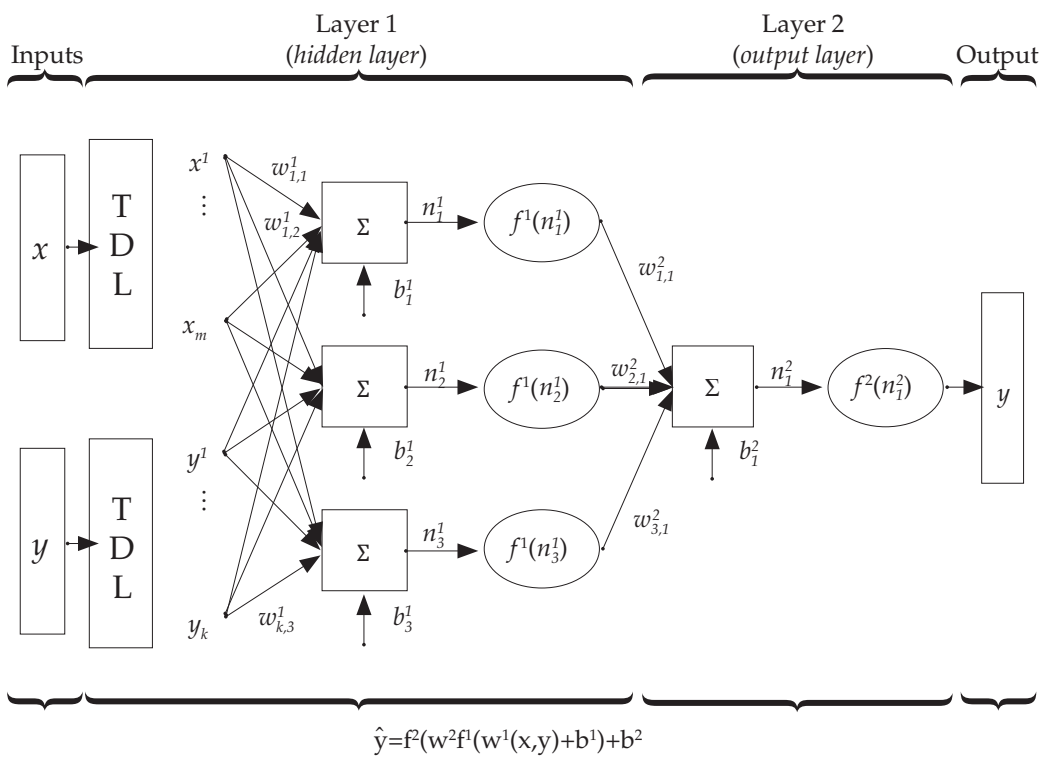

Figure 3. Sample NARX-ANN with two layers

The first (hidden) layer consists of two tapped delayed lines (TDL) that contain the vectors of lagged inputs; three bias scalar terms $\left(b_{1}^{1}, b_{2}^{1}, b_{3}^{1}\right)$ with a constant input of 1 ; all $w^{1}$ weights that connect each input with the three neurons (i.e., the sum operators and their corresponding activation functions, $\left.f^{1}\right)$. The second layer consists of a single neuron with an operator that sums the product of the weights $\left(w_{1,1}^{2}, w_{2,1}^{2}, w_{3,1}^{2}\right)$ and the result from the neurons in the first layer $\left(f^{1}\left(n_{1}^{1}\right), f^{1}\left(n_{2}^{1}\right), f^{1}\left(n_{3}^{1}\right)\right)$; one bias scalar term, $b_{1}^{2}$, with a constant input of 1 ; and the second activation function $\left(f^{2}\left(n_{1}^{2}\right)\right)$, which yields the output.

Source: The authors based on Hagan et al. (2014) and Di Piazza et al. (2016). 
The structure of the ANN in the NARX model depends on the number of layers and neurons, and the choice of transfer functions. About the number of layers, a two-layer network (i.e., one hidden and one output layer) is all that is necessary in most cases (Zhang et al., 1999; Witten et al., 2011), and it is the most commonly used ANN in economic and financial applications (McNelis, 2005). The number of neurons in the hidden layers corresponds to the complexity of the function that is being approximated, whereas the number of neurons in the output layer depends on the number of outputs - usually, one per output-. Regarding the transfer functions in NARX-ANN models, a customary choice for hidden layers is the sigmoid transfer function $\left(f^{1}=1 /(1\right.$ $\left.\left.+e^{-n}\right)\right)$, whereas a linear transfer function $\left(e . g ., f^{2}=n\right)$ is the standard for the output layer (Hagan et al., 2014).

\subsection{Training the NARX Artificial Neural Network Model}

The learning process of an ANN consists of adjusting all $w$ and $b$ parameters in the structure in order to minimize the error between the prediction and the target (i.e., observed) value for a set of observations. This process, also called training, is somewhat similar to fitting the parameters of a regression model in econometrics.

The most popular ANN learning algorithm is backpropagation. ${ }^{6}$ Backpropagation learns by iteratively processing a dataset of training observations, comparing network's prediction for each observation with the target value. All parameters $w$ and $b$ are modified in backwards direction, from the output layer, through each layer down to the first layer. In our case, for predicting continuous variables the fit of the ANN is typically measured as a function of square errors, say the root mean square error $\left(R M S E=\sqrt{\sum_{i=1}^{n}(\hat{y}-y)^{2} / n}\right)$.

As before, our goal under the nowcasting objective is to provide useful out-of-sample predictions. In this sense, machine learning methods attempt to avoid the overfitting problem. The overfitting problem may be described as the model's ability to succeed at fitting in-sample but to fail at fitting out-ofsample (Shmueli, 2010; Varian, 2014). Overfitting occurs when a model depends too strongly on the details of the particular examples used to produce those (Witten et al., 2011). In this sense, the role of ANN $s$ is to provide general non-linear mappings between a set of input variables and a set of output

6 A complete explanation on the functioning of the backpropagation algorithm is beyond the scope of our paper. The interested reader may refer to Bishop (1995), Mitchell (1997), and Han and Kamber (2006). 
variables. As in Bishop (1995), the goal is not to memorize the training data, but to model the underlying generator of the data.

In the case of ANN $\mathrm{s}$ the overfitting problem may be avoided by means of early stopping. ${ }^{7}$ In early stopping, instead of allowing the algorithm to attain the minimal in-sample error (at the expense of out-of-sample error), the minimization process is halted before the complexity of the solution inhibits its generalization capability. In this sense, if training is stopped before the minimum in-sample is reached, then the ANN will effectively be using fewer parameters and will be less likely to overfit.

An intuitive and customary early stopping criterion is cross-validation. Data is divided into three independent datasets: training, validation and test. The three datasets are usually selected with an approximate $70 \%, 15 \%, 15 \%$ random allocation, respectively (Hagan et al., 2014). The training dataset is used to train the network (i.e., to minimize the in-sample error between the prediction and the target value). The validation dataset is used simultaneously (i. e., during training) to check how the estimated parameters fit out-of-sample data. When the error on the validation dataset increases for several iterations of the training algorithm, the training is halted, and the parameters that produced the minimum error on the validation dataset are used as the final trained network parameters. After training the network, the error obtained on the test dataset is used to check the future performance of the ANN on out-of-sample data. With cross-validation, a firewall principle (Mullainathan \& Spiess, 2017) is implemented to guarantee that none of the data involved in the training is used to evaluate the out-of-sample predictive performance of the network.

\subsection{A Committee of Artificial Neural Networks}

We train a NARX-ANN model with two layers, as the one presented in Figure $3 .^{8}$ Our choice of transfer functions is the customary sigmoid and linear transfer functions for the hidden and output layers, respectively. The model's output and inputs are the logarithmic returns of the corresponding series. Consistent with the year-long seasonality of economic activity, the lag order of the output

7 The other most common method to avoid overfitting is regularization. In regularization, the performance of the ANN includes a term that penalizes network complexity and -thus - forces the function to be smooth and to attain a general mapping of the inputs and outputs. Hagan et al. (2014) demonstrate that there is an approximate equivalence between early stopping and regularization.

8 The NARX-ANn model was implemented in Matlab's Neural Network Toolbox. 
variable $\left(y_{t}\right)$ is twelve months, whereas exogenous variables are not lagged (i. e., only concurrent values of payment instruments are used). ${ }^{9}$ Regarding the number of neurons, several scenarios are considered to implement an empirical tuning procedure to pick the choice with the best estimated performance (Mullainathan \& Spiess, 2017). To avoid overfitting, we employ early stopping by cross-validation with a $70 \%, 15 \%$, and $15 \%$ random allocation for the training, validation, and test datasets. ${ }^{10}$

A single training process of any ANN may not produce optimal performance, because of the possibility of reaching a local minimum of the performance surface (Hagan et al., 2014). This is caused by the ANNs' dependence on the initialization parameters. Therefore, we implement the committee method (Bishop, 1995; Mitchell, 1997; Hastie et al., 2013; Hagan et al., 2014). Under this method we run 1,000 independent training processes for each of the scenarios considered, and estimate their joint output, i. e., the simple unweighted average. This is useful because the joint output of the committee of networks will usually achieve higher performance than any single network used in isolation (Bishop, 1995; Hagan et al., 2014), and because it enables to obtain a density forecast for the target variable (Chakraborty \& Joseph, 2017).

\section{Main Results and Validations}

We employ two standard measures of out-of-sample (i.e., on the test dataset) performance. First, the root mean square error (RMSE) between the observed and the predicted logarithmic returns of ISE. Second, the correlation $(\bar{r})$ between the observed and the predicted logarithmic returns of ISE.

Table 2 exhibits the average of these two measures, estimated on the 1,000 independent training processes of each scenario, denoted as $\overline{R M S E}$ and $\bar{r}$. Standard deviation for both measures are reported in brackets. In the four scenarios considered, both measures of average out-of-sample performance appear to be fair. The measures do not change noticeably with variations in the number of neurons. The scenario that results in the lowest coefficient of variation (i.e., dispersion relative to the mean) is the one with 30 neurons.

9 As ISE is released with an approximate two-month lag, the lag order of the output variable starts at the second lag. Including lagged, exogenous variables did not improve the prediction performance; for parsimony, the output variable is the only one with lags.

10 Performance is robust to changes in the allocation method. Non-random allocations (e.g., interleaved non-overlapping blocks, successive blocks) of training, validation, and test sets delivered similar performance. 
Table 2. Predictive out-of-sample performance for selected scenarios of number of neurons in the hidden layer

\begin{tabular}{ccccc}
\hline & \multicolumn{4}{c}{ Number of Neurons } \\
\cline { 2 - 5 } & 10 & 20 & 30 & 40 \\
\hline \multirow{2}{*}{ RMSE } & .0084 & .0082 & .0081 & .0082 \\
& {$[.0022]$} & {$[.0018]$} & {$[.0016]$} & {$[.0017]$} \\
\hline \multirow{2}{*}{$\bar{r}$} & .9869 & .9873 & .9875 & .9871 \\
\cline { 2 - 5 } & {$[.0072]$} & {$[.0061]$} & {$[.0048]$} & {$[.0055]$} \\
\hline
\end{tabular}

$\overline{R M S E}$ corresponds to the average RMSE estimated on 1,000 independent training processes for each scenario. $\bar{r}$ corresponds to the average correlation coefficient between the observed and predicted log-return series for each scenario. Standard deviation is reported in brackets. The highest performance scenario is in bold.

Source: Authors' calculations.

Figure 4 displays three series, corresponding to the 30-neuron scenario: first, the observed ISE logarithmic return series, displayed as an empty circle for each observation (circles' centers correspond to the observed series);

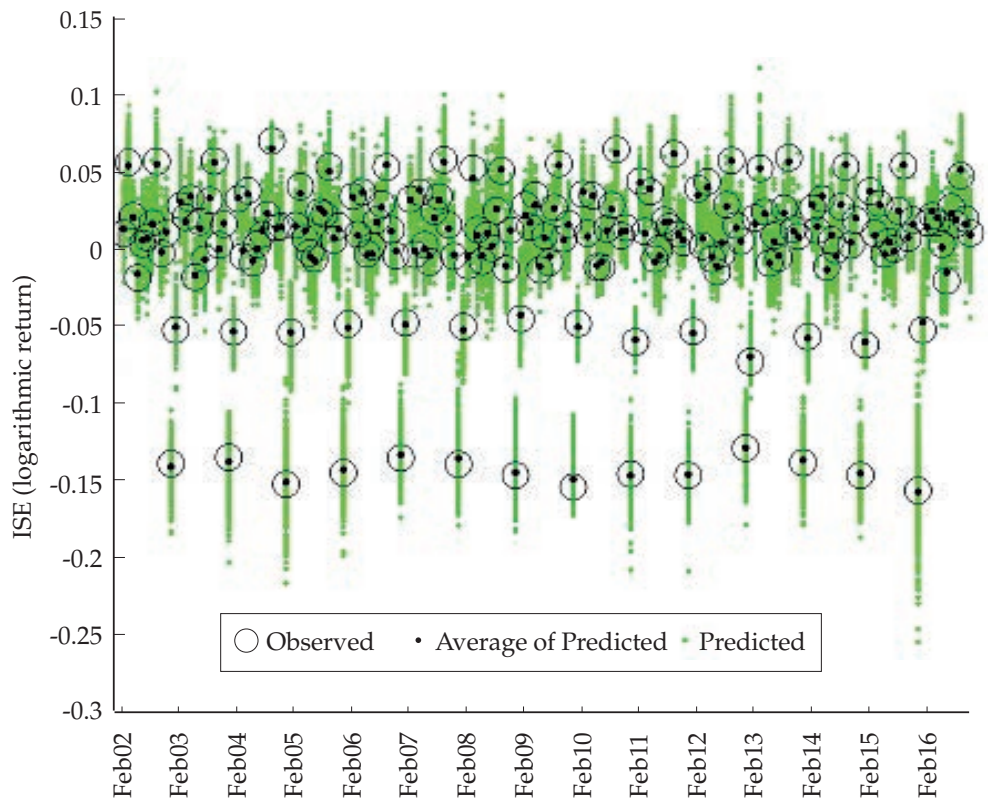

Figure 4. Observed (empty circles), predicted (green dots), and average of predicted (black dots) ISE logarithmic returns

Predicted ISE series correspond to 1,000 independent training processes of the scenario corresponding to 30 neurons.

Source: DANE and authors' calculations. 
second, 1,000 predicted logarithmic return series, displayed as a green dot for each prediction, for each observation; third, the corresponding average predicted logarithmic return, portrayed as a black dot for each observation. It is apparent that the 1,000 predictions scatter around the target variable; in some cases, the dispersion around the target variable is high. As expected under a committee of networks method, the average predicted logarithmic returns (black dots) are particularly close to the observed logarithmic returns (empty circles).

Based on the committee of networks' prediction (i.e., the average prediction of the 1,000 independent training processes), we calculate the committees' corresponding out-of-sample performance measures, $\overline{\overline{R M S E}}$ and $\overline{\bar{r}}$, in Table 3. As expected, the performance increases manifestly: For the 30-neuron scenario, $\overline{R M S E}$ and $\overline{\overline{R M S E}}$, which signifies a 67.90 percent decrease in outof-sample error. Taking into account that Hinds et al. (2017) point out that being able to nowcast the United Kingdom's economic quarterly growth with a RMSE around .0030 is relatively impressive, it is fair to say that nowcasting economic activity in the Colombian case with our choice of dataset and predictive method is feasible. ${ }^{11}$

Table 3. Committee of networks' predictive (out-of-sample) performance for selected scenarios of number of neurons in the hidden layer

\begin{tabular}{ccccc}
\hline & \multicolumn{5}{c}{ Number of Neurons } \\
\cline { 2 - 5 } & 10 & 20 & 30 & 40 \\
\hline$\overline{\overline{R M S E}}$ & .0042 & .0029 & .0026 & .0026 \\
\hline $\bar{r}$ & .9971 & .9984 & .9987 & .9987
\end{tabular}

$\overline{\overline{R M S E}}$ corresponds to the RMSE calculated with the average predicted log-return on the 1,000 independent training processes of each scenario. $\bar{r}$ corresponds to the correlation coefficient between the observed and the average predicted log-return on the 1,000 independent training processes of each scenario. The highest performance scenario is in bold.

Source: Authors' calculations.

11 Based on data extracted from the United Kingdom's Office for National Statistics (www.ons.gov.uk), the average quarterly absolute change of GDP is .0067 for the period studied by Hinds et al. (2017). Thus, the ratio of RMSE to the average quarterly absolute change is about $0.0030 /(0.0067=.4476)$; that is, the relative size of the error is about 45 percent. In the case of ISE, the average monthly absolute change is .0361. For the 30-neuron scenario, the $\overline{R M S E}$ and $\overline{\overline{R M S E}}$ are .0081 and .0026 , therefore their ratio to the average monthly absolute change is $0.0081 /(0.0361=.2244)$ and $0.0026 /(0.0361=.0720)$. That is, the relative size of the error is manifestly lower. 
Figure 5 exhibits the density forecast (i.e., distribution of errors) corresponding to the 30-neuron scenario. It compares the out-of-sample errors attained by each one of the 1,000 predictions to those attained by the committee ( $i$. $e$. , the average prediction). As expected, the committee's prediction exhibits a manifestly lower dispersion of errors: The errors' range decreases from $[-.1006, .0930]$ to $[-.0069, .0070]$, with negligible variation in the mean error.

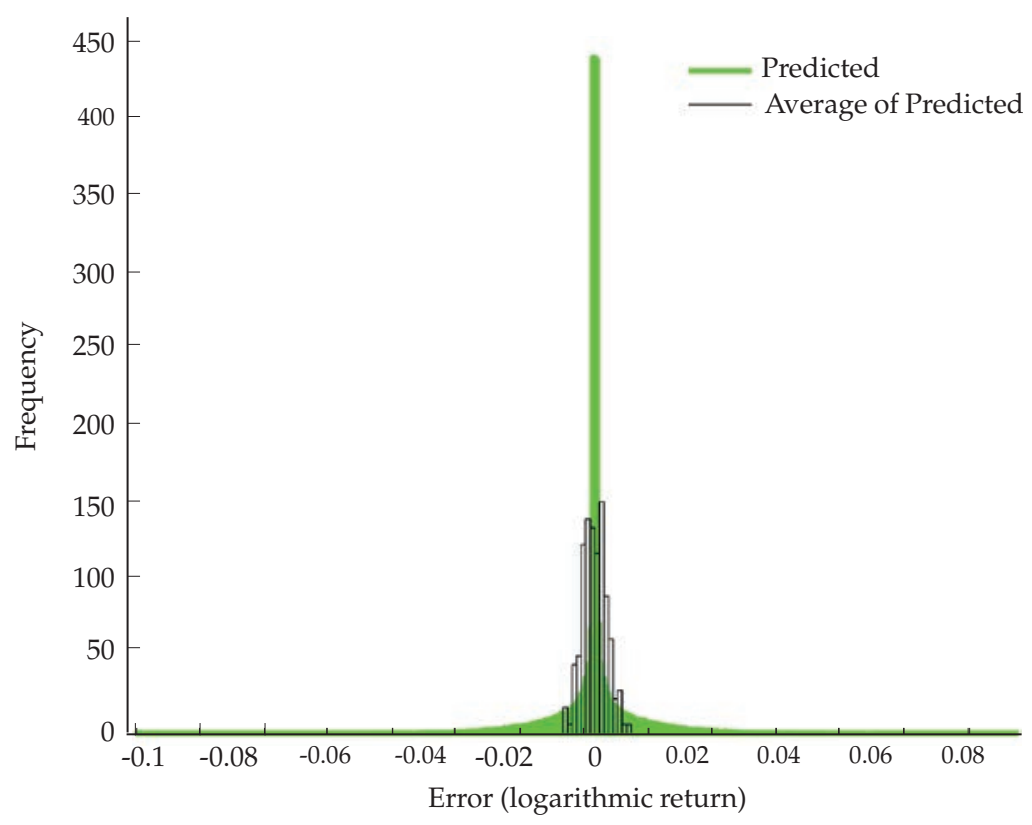

Figure 5. Distribution of errors (logarithmic return) of predicted and the average of predicted

Predicted correspond to the errors of 1,000 independent training processes of the scenario corresponding to 30 neurons.

Source: Authors' calculations.

There are other validation tools besides attaining a high-performance model in terms of low out-of-sample prediction error and fit. As in Hagan et al. (2014), there are two basic properties of accurate prediction models that should be regarded. First, prediction errors should be uncorrelated with each other. Second, prediction errors should be uncorrelated with the exogenous inputs sequence. In both cases, if errors were correlated the prediction could be further improved (Hagan et al., 2014).

Table 4 presents the incidence of the significant correlation of prediction errors. It is calculated as the fraction of cases in which the 95 percent confidence intervals are exceeded in any of the twenty lags considered, with respect 
to 1,000 independent training processes of each scenario. The incidence of both types of correlation of prediction errors is rather high in all scenarios.

Table 4. Incidence of significant correlation of prediction errors

\begin{tabular}{lcccc}
\hline & \multicolumn{4}{c}{ Number of Neurons } \\
\cline { 2 - 5 } & 10 & 20 & 30 & 40 \\
\hline Autocorrelation & .8450 & .7860 & .7450 & .7190 \\
Correlation with Exogenous Inputs & .9680 & .9190 & .9230 & .9320
\end{tabular}

Calculated as the fraction of cases in which the 95 percent confidence intervals are exceeded in any of the twenty lags considered, with respect to 1,000 independent training processes of each scenario. Source: Authors' calculations.

The standard solution is to change the lag order of both inputs. This has no substantial effects on the incidence of exceedances with respect to the 95 percent confidence intervals, and adds computation time - when lags are increased-. However, taking into account the performance (see Tables 2 and 3), correcting for these two correlations in search of higher performance may be secondary.

An additional validation comes in the form of verifying whether the NARX-ANN model outperforms a non-linear autoregressive artificial neural network model (NAR-ANN). ${ }^{12}$ This validation enables to assess the contribution of electronic payments data to reducing economic activity nowcast error. Table 5 compares the best performing NARX-ANN and the NAR-ANN models by their RMSE performance..$^{13}$ The NARX-ANN attains a decrease in $\overline{R M S E}$ and $\overline{\overline{R M S E}}$ of 24.29 and 51.85 percent, respectively. ${ }^{14}$ Thus, we validate that electronic payments data significantly reduces the nowcast error of a benchmark model.

12 The implementation of the NAR-ANN model replicates the NARX-ANN in all aspects but excludes the exogenous inputs (i.e., electronic payments data). That is, in [2] and in Figure 3 all $x$ variables are omitted. Not only a benchmark based on ANN allows a fair comparison for the NARX-ANN model, but it is a judicious choice as well because it encompasses linear and non-linear models.

13 Table 8 (in the Appendix) exhibits the performance of the NAR-ANN model for the four number-of-neuron scenarios. The best performing NAR-ANN by $\overline{R M S E}$ and $\overline{\overline{R M S E}}$ are the 10-neuron and 40-neuron models, respectively. The best performing NARX-ANN is the 30-neuron model (see Tables 2 and 3).

14 Correspondingly, the mean and range of out-of-sample errors is manifestly lower in the NARX-ANN model: The mean and range of errors in the NAR-ANN'S Committee are $-1.3247 \times 10^{-4}$ and $[-.0298, .0244]$, respectively, whereas in the NARX-ANN's committee they are $-5.4450 \times 10^{-5}$ and $[-.0069, .0070]$. Furthermore, comparing tables 2,3 and 8 , the worst performing NARX-ANN (the 10-neuron model) outperforms the best NAR-ANN model. 
Table 5. Comparison of predictive out-of-sample performance for the best performing NAR-ANN and NARX-ANN models

\begin{tabular}{lccc}
\hline & NAR $^{\mathrm{a}}$ & $\mathrm{NARX}^{\mathrm{b}}$ & Change $(\%)^{\mathrm{c}}$ \\
\hline$\overline{R M S E}$ & .0107 & .0081 & -24.29 \\
$\overline{\overline{R M S E}}$ & .0054 & .0026 & -51.85
\end{tabular}

$\overline{R M S E}$ corresponds to the average RMSE estimated on 1,000 independent training processes for each scenario. $\overline{\overline{R M S E}}$ corresponds to the RMSE calculated with the average predicted log-return on the 1,000 independent training processes of each scenario. ${ }^{\text {a }}$ The best performing NAR-ANN by $\overline{R M S E}$ and $\overline{\overline{R M S E}}$ are the 10-neuron and 40-neuron models, respectively (see Table 8, in the Appendix). ${ }^{\mathrm{b}}$ The best performing NARX-ANN is the 30-neuron model (see Tables 2 and 3).

Source: Authors' calculations.

\section{Final Remarks}

In this article we address the economic activity nowcasting issue. We attempt to nowcast changes in the Economic Monitoring Index (Indicador de Seguimiento a la Economía, ISE), which is a two-month-lagged monthly indicator of the economic activity in Colombia. Unlike most literature on the subject, yet concurrent with the work of Galbraith and Tkacz (2017), we rely on electronic payment instruments data as high-frequency indicators from which reliable signals of economic activity are to be extracted. Regarding the methodological approach, as nowcasting is better understood as predictive modeling (instead of explanatory modeling), we rely on the well-documented performance and flexibility of artificial neural networks (ANNs) for prediction.

Results suggest that electronic payment instruments data and a NARX (Non-linear AutoRegressive eXogenous) ANN enable us to nowcast ISE with fair accuracy, about two months before its release. Besides, a committee of ANNs attained a further enhanced predictive performance. Some issues related to the correlation of prediction errors (e.g., autocorrelation) are present and could not be circumvented by standard means (e.g., varying the lag order of inputs); nonetheless, it is debatable whether correcting for correlation of prediction errors to enhance performance is a primary concern. Also, we validate that the NARX-ANN model outperforms a benchmark non-linear autoregressive artificial neural network model (NAR-ANN); this confirms the contribution of electronic payments data to reducing the economic activity nowcast error. Therefore, we conclude that it possible and convenient to nowcast changes in the Colombian short-term economic activity indicator (i.e., ISE) with a set of electronic payment instruments data. 
Some extensions for our work are readily available. First, we focus on nowcasting, but electronic payment instruments data and the ANN model may be useful for forecasting as well; that is, instead of making a reliable current-period estimate of economic activity, we could attempt to predict one or several periods ahead. Second, as suggested in Evans (2005), it may be possible to attain a high-frequency (e.g., daily, weekly) estimate of economic activity as payments data becomes available with a lower lag (e. g., one-day lag). Third, the nowcasting outcome could feed other models that may profit from a current-period estimate of economic activity. Fourth, evaluating whether adding other traditional macroeconomic and financial variables compatible with the nowcasting objective (e.g., interest rates, stock indexes) may further enhance the predictive performance. Fifth, debit and credit card data should be added as inputs. In our case they are not considered because the corresponding data is reported with a lag that is incompatible with a nowcasting exercise. It is arguable that omitting credit and debit card data is nowadays unimportant because credit and debit card payments contribute with about 4 percent of all electronic payments by value of operations in Colombia (as of 2016), and because the attained predictive performance is fair. Yet, the dynamics of payment habits and technology may require including them in the near future. Finally, a reliable high-frequency input of cash usage is worth adding.

\section{References}

Aiken, M. (2000). Forecasting the United States gross domestic product with a neural network. Journal of International Information Management, 9(1), 67-75.

Angelini, E., Di Tollo, G., \& Roli, A. (2008). A neural network approach for credit risk evaluation. The Quarterly Review of Economics and Finance, 48, 733-755. DoI: 10.1016/j.qref.2007.04.001

Bańbura, M., Giannone, D., Modugno, M., \& Reichlin, L. (2013). Nowcasting and the real-time data flow. In G. Elliott \& A. Timmermann (Eds.), Handbook of economic forecasting (pp. 195-237). Amsterdam: North Holland-Elsevier.

Banco de la República. (2017). Reporte de sistemas de pago. Colombia.

Bec, F., \& Mogliani, M. (2015). Nowcasting French GDP in real-time with surveys and 'blocked' regressions: combining forecasts or pooling information? International Journal of Forecasting, 31, 1021-1042. Dor: 10.1016/j. ijforecast.2014.11.006

Bell, V., Wah Co, L., Stone, S., \& Wallis, G. (2014). Nowcasting UK GDP growth. Quarter Bulletin, Q1, Bank of England. 
Bishop, C. M. (1995). Neural networks for pattern recognition. Oxford: Clarendon Press.

Bragoli, D. (2017). Now-casting the Japanese economy. International Journal of Forecasting, 33, 390-402. DoI: 10.1016/j.ijforecast.2016.11.004

Chakraborty, C., \& Joseph, A. (2017). Machine learning at central banks. Staff Working Paper, 674, Bank of England.

Chaudhuri, T. D., \& Ghosh, I. (2016). Artificial neural network and time series modeling based approach to forecasting the exchange rate in a multivariate framework. Journal of Insurance and Financial Management, 1(5), 92-123.

Choi, H., \& Varian, H. (2012). Predicting the present with Google Trends. Economic Record, 88, 2-9. Dor: 10.1111/j.1475-4932.2012.00809.x

Demyanyk, Y., \& Hasan, I. (2009). Financial crises and bank failures: a review of prediction methods. Federal Reserve Bank of Cleveland Working Papers Series, 09-04R, September.

Departamento Administrativo Nacional de Estadística (DANE). (2016). Metodología general. Indicador de seguimiento a la economía ISE. Retrieved from https:/ / www.dane.gov.co/files/investigaciones/fichas/cuentas-nacionales /DSO-CT-MET-Metodologia-General-Indicador-de-Seguimientoa-la-Economia-ISE-Agosto-2016.pdf

Departamento Administrativo Nacional de Estadística (DANE). (2017). Metodología general. Cuentas trimestrales (СТ) base 2005. Retrieved from http:/ / www.dane.gov.co/files/investigaciones/fichas/Cuentas_trimestrales_ b2000_marzo_17.pdf

Di Piazza, A., Di Piazza, M. C., \& Vitale, G. (2016). Solar and wind forecasting by NARX neural networks. Renewable Energy and Environmental Sustainability, 1(39). DOI: 10.1051/rees/2016047

Evans, M. D. D. (2005). Where are we now? Real-time estimates of the macroeconomy. International Journal of Central Banking, 1(2), 127-175.

Galbraith, J. W., \& Tkacz, G. (2017). Nowcasting with payments system data. International Journal of Forecasting. DoI: 10.1016/j.ijforecast.2016.10.002

Giannonne, D., Reichlin, L., \& Small, D. (2008). Nowcasting: the real-time informational content of macroeconomic data. Journal of Monetary Economics, 55, 665-676. DoI: 10.1016/j.jmoneco.2008.05.010

Hagan, M. T., Demuth, H. B., Beale, M. H, \& De Jesús, O. (2014). Neural network design. Martin Hagan: Oklahoma.

Han, J., \& Kamber, M. (2006). Data mining: concepts and techniques. San Francisco: Morgan Kaufman Publishers.

Hastie, T., Tibshirani, R., \& Friedman, J. (2013). The elements of statistical learning. New York: Springer. 
Hinds, S., Rimmington, L., Dance, H., Gillham, J., Sentence, A., \& Hawksworth, J. (2017). A machine learning approach to estimating current GDP growth. UK Economic Outlook, July, PWC.

Jalil, M., \& Misas, M. (2006). Evaluación de pronósticos del tipo de cambio utilizando redes neuronales y funciones de pérdida asimétricas. Borradores de Economía, 376, Banco de la República.

Kohzadi, N., Boyd, M. S., Kaastra, I., Kermanshahi, B. S., \& Scuse, D. (1995). Neural networks for forecasting: an introduction. Canadian Journal of Agricultural Economics, 3(43), 463-474. Dor: 10.1111/j.1744-7976.1995.tb00135.x

Lin, T., Horne, B. G., Tino, P., \& Giles, C. L. (1996). Learning long-term dependencies in NARX recurrent neural networks. IEEE Transactions on Neural Networks, 7(6), 1329-1338.

Mahmoud, S., Lofti, A., \& Langensiepen, C. (2013). Behavioral pattern identification and prediction in intelligent environments. Applied Soft Computing, 13, 1813-1822. DoI: 10.1016/j.asoc.2012.12.012

McAndrews, J. (1994). The automated clearinghouse system: moving toward electronic payment. Business Review, July/August, Federal Reserve Bank of Philadelphia, 15-23.

McLaren, N. (2011). Using internet search data as economic indicators. Quarterly Bulletin, Q2, Bank of England, 134-140.

McNelis, P. D. (2005). Neural networks in finance. Burlington: Elsevier.

Misas, M., López, E., Arango, C., \& Hernández, J. N. (2003). La demanda de efectivo en Colombia: una caja negra a la luz de las redes neuronales. Borradores de Economía, 268, Banco de la República.

Mitchell, T. M. (1997). Machine learning. Boston: McGraw-Hill.

Mullainathan, S., \& Spiess, J. (2017). Machine learning: an applied econometric approach. Journal of Economic Perspectives, 31(2), 87-106. Dor: 10.1257/ jep.31.2.87

Sarlin, P. (2014). On biologically inspired predictions of the global financial crisis. Neural Computing and Applications, 24(3), 663-673. DoI: 10.1007/ s00521-012-1281-y

Shmueli, G. (2010). To explain or to predict? Statistical Science, 25(3), 289-310. DOI: $10.1214 / 10-S T S 330$

Tiffin, A. (2016). Seeing in the dark: a machine-learning approach to nowcasting in Lebanon. IMF Working Paper, WP/16/56, International Monetary Fund.

Tkacz, G., \& Hu, S. (1999). Forecasting GDP growth using artificial neural networks. Bank of Canada Working Paper Series, 99-3, Bank of Canada.

Varian, H. R. (2014). Big data: new tricks for econometrics. Journal of Economic Perspectives, 28(2), 3-28. DoI: 10.1257/jep.28.2.3 
Witten, I. H., Frank, E., \& Hall, M. A. (2011). Data mining: practical machine learning tools and techniques. Burlington: Morgan Kaufman Publishers.

Zhang, G., Hu, M. Y, Patuwo, B. E., \& Indro, D. C. (1999). Artificial neural networks in bankruptcy prediction: general framework and cross-validation analysis. European Journal of Operational Research, 116, 16-32.

Zukime, M., \& Junoh, M. (2004). Predicting GDP growth in Malaysia using knowledge-based economy indicators: a comparison between neural network and econometric approaches. Sunway College Journal, 1, 39-50.

\section{Appendix}

Table 6. Descriptive statistics of output and inputs

\begin{tabular}{llccccc}
\hline & Series & Mean & $\begin{array}{c}\text { Standard } \\
\text { Deviation }\end{array}$ & Skewness & Kurtosis & $\begin{array}{c}\text { Jarque Bera } \\
\text { (p-value) }\end{array}$ \\
\hline ISE & & 0.004 & 0.051 & -1.747 & 5.727 & .000 \\
\multirow{2}{*}{$\begin{array}{l}\text { Value of } \\
\text { Operations }\end{array}$} & ACH Colombia & 0.017 & 0.160 & -0.854 & 5.749 & .000 \\
& ACH Cenit & 0.009 & 0.290 & -1.412 & 9.098 & .000 \\
& Cedec & -0.005 & 0.140 & -0.569 & 5.862 & .000 \\
$\begin{array}{l}\text { Number } \\
\text { of Opera- }\end{array}$ & ACH Colombia & 0.021 & 0.111 & -0.872 & 5.824 & .000 \\
tions & ACH Cenit & 0.026 & 0.236 & -1.241 & 8.336 & .000 \\
\hline
\end{tabular}

Estimated on logarithmic returns of monthly series from January 2001 to December 2016 (191 observations). Inputs corresponding to values are at constant prices, deflated by the consumer price index.

Source: Authors' calculations.

Table 7. Electronic payment instruments (2001-2016)

\begin{tabular}{lcccccc}
\hline & \multicolumn{3}{c}{ Number of Operations } & \multicolumn{3}{c}{ Value of Operations } \\
\cline { 2 - 7 } Year & $\begin{array}{c}\text { Debit and } \\
\text { Credit Cards }\end{array}$ & $\begin{array}{c}\text { Transfers via } \\
\text { ACHs }\end{array}$ & Cheques & $\begin{array}{c}\text { Debit and } \\
\text { Credit Cards }^{\mathrm{a}}\end{array}$ & $\begin{array}{c}\text { Transfers via } \\
\text { ACHs }\end{array}$ & Cheques \\
\hline 2001 & 0,33 & 0,04 & 0,63 & 0,01 & 0,15 & 0,83 \\
2002 & 0,37 & 0,06 & 0,57 & 0,01 & 0,18 & 0,80 \\
2003 & 0,41 & 0,09 & 0,49 & 0,02 & 0,22 & 0,76 \\
2004 & 0,47 & 0,11 & 0,42 & 0,02 & 0,27 & 0,71 \\
2005 & 0,52 & 0,13 & 0,36 & 0,02 & 0,32 & 0,66 \\
2006 & 0,53 & 0,15 & 0,32 & 0,02 & 0,34 & 0,63 \\
2007 & 0,51 & 0,22 & 0,26 & 0,02 & 0,41 & 0,57
\end{tabular}




\begin{tabular}{ccccccc}
\hline \multirow{2}{*}{ Year } & \multicolumn{3}{c}{ Number of Operations } & \multicolumn{3}{c}{ Value of Operations } \\
\cline { 2 - 6 } & $\begin{array}{c}\text { Debit and } \\
\text { Credit Cards }\end{array}$ & $\begin{array}{c}\text { Transfers via } \\
\text { ACHs }\end{array}$ & Cheques & $\begin{array}{c}\text { Debit and } \\
\text { Credit Cards }{ }^{\mathrm{a}}\end{array}$ & $\begin{array}{c}\text { Transfers via } \\
\text { ACHs }\end{array}$ & Cheques \\
\hline 2008 & 0,49 & 0,32 & 0,20 & 0,02 & 0,46 & 0,52 \\
2009 & 0,50 & 0,35 & 0,15 & 0,02 & 0,50 & 0,48 \\
2010 & 0,52 & 0,36 & 0,12 & 0,02 & 0,55 & 0,43 \\
2011 & 0,54 & 0,36 & 0,10 & 0,03 & 0,58 & 0,39 \\
2012 & 0,56 & 0,35 & 0,08 & 0,03 & 0,63 & 0,34 \\
2013 & 0,58 & 0,35 & 0,07 & 0,03 & 0,68 & 0,29 \\
2014 & 0,59 & 0,35 & 0,06 & 0,03 & 0,70 & 0,26 \\
2015 & 0,60 & 0,35 & 0,05 & 0,04 & 0,73 & 0,24 \\
2016 & 0,62 & 0,34 & 0,04 & 0,04 & 0,74 & 0,22 \\
\hline
\end{tabular}

Contribution to the number and value of operations. Payments cleared and settled in the books of banks are not considered.

a Purchases with debit and credit cards.

Source: Banco de la República (2017).

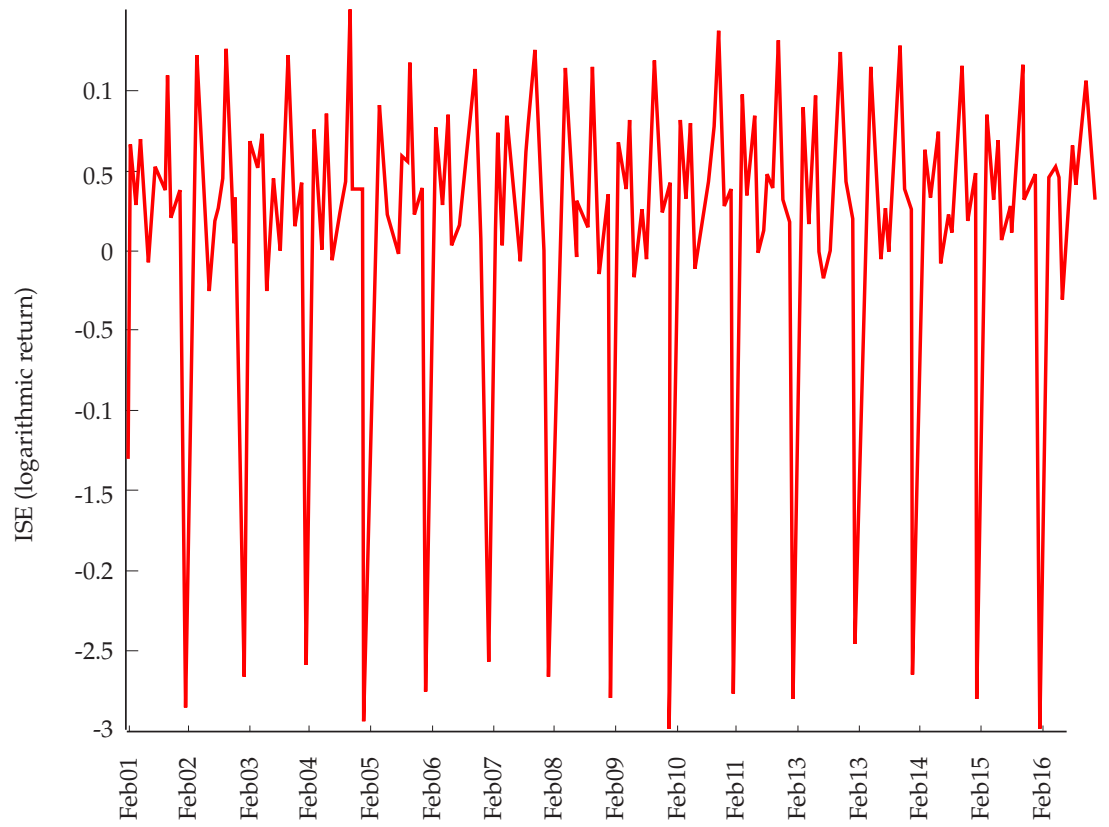

Figure 6. Standardized logarithmic returns of ISE

Non-seasonally adjusted, at constant prices, revised index.

Source: DANE. 

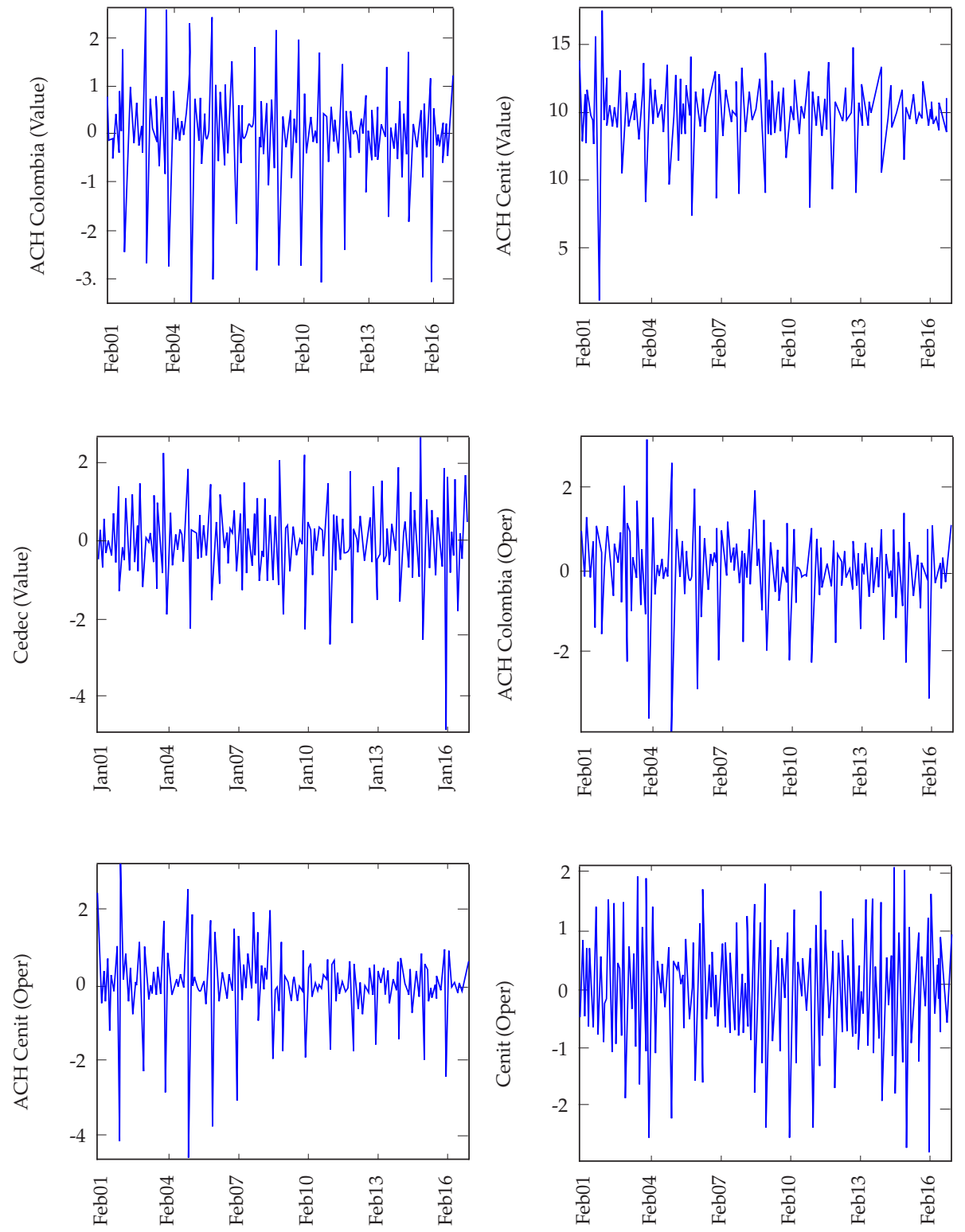

Figure 7. Standardized logarithmic returns of electronic payment instruments data First row corresponds to logarithmic returns on the value (in constant Colombian pesos, deflated by the consumer price index) and the second to logarithmic returns on the number of operations. Source: AcH Colombia and Banco de la República. 
Table 8. NAR-ANN predictive out-of-sample performance for selected scenarios of number of neurons in the hidden layer

\begin{tabular}{ccccc}
\hline & \multicolumn{4}{c}{ Number of Neurons } \\
\cline { 2 - 5 } & 10 & 20 & 30 & 40 \\
\hline$\overline{R M S E}$ & .0107 & .0114 & .0121 & .0126 \\
& {$[.0017]$} & {$[.0025]$} & {$[.0030]$} & {$[.0032]$} \\
$\bar{r}$ & .9784 & .9760 & .9732 & .9706 \\
$\overline{\overline{R M S E}}$ & {$[.0068]$} & {$[.0106]$} & {$[.0135]$} & {$[.0193]$} \\
$\overline{\bar{r}}$ & .0075 & .0065 & .0059 & .0054 \\
\hline
\end{tabular}

$\overline{R M S E}$ corresponds to the average RMSE estimated on 1,000 independent training processes for each scenario. $\bar{r}$ corresponds to the average correlation coefficient between the observed and predicted log-return series for each scenario. Standard deviation is reported in brackets. $\overline{\overline{R M S E}}$ corresponds to the RMSE calculated with the average predicted log-return on the 1,000 independent training processes of each scenario. $\bar{r}$ corresponds to the correlation coefficient between the observed and the average predicted log-return on the 1,000 independent training processes of each scenario. The highest performance scenario is in bold.

Source: Authors' calculations. 
